\title{
THE TECHNOLOGY TRIANGLE
}

\section{How The Government/Business/University Triangle Works in Massachusetts}

\section{BY MICHAEL S. DUKAKIS \\ Governor \\ Commonwealth of Massachusetts}

I am going to try to keep this reasonably brief because you've got two very distinguished speakers to follow, each of whom knows a lot more about materials research than I do. And if confession is good for the soul, I suppose I ought to confess: I attended Brookline, Massachusetts, High School and as Dick Siegel will tell you (who is one of your members and was a year behind me), I did pretty well there. And then I went off to a small Quaker school nine miles southwest of Philadelphia where, in order to fulfill my science requirement, I decided to take general physics. At that time, I was supposed to be a pre-med-although I wasn't quite sure what I was-and I figured I'd start with physics, which I had not had in high school. And to say that I got a charitable D-minus would be an overstatement of the case. I never could grasp the subject despite a kindly professor who tried as best he could to help me through. And the fact that I got a charitable D-minus in physics at Swarthmore College probably has as much to do with the fact that I'm now in politics as any other single thing that I can think of. So I come before you with a certain degree of awe, and also with special appreciation of how important science is to those of us in positions of political leadership these days, and how increasingly we have to rely on you as we try to make some very tough decisions. And I want to talk about that briefly before leaving you and turning you over to your speakers, one of whom is from North Carolina where we are copying some things that have already been done, and the other of whom is a native of Massachusetts, and it's nice to have you back, Jay [Keyworth], and have you with us.

And let me also begin by thanking you for what happened last year. I don't know how many of you are aware of it, but we displaced you in this room in order to have our victory party on election night, and you were good enough to do it, which is one of the reasons why I at least wanted to come back to say thanks to all of you.

As I'm sure you all know, you're in a state where the government/business/university triangle has been about as highly developed as in any other state of the country. And as the 65th and 67th governor (and I won't tell you who the 66th was, or why that happened, except to say that it's nice to be back knowing something about the job the second time-a lot more than I knew the first time), I have been particularly concerned about this triangle because for this state and for it's economic future, the nurturing and

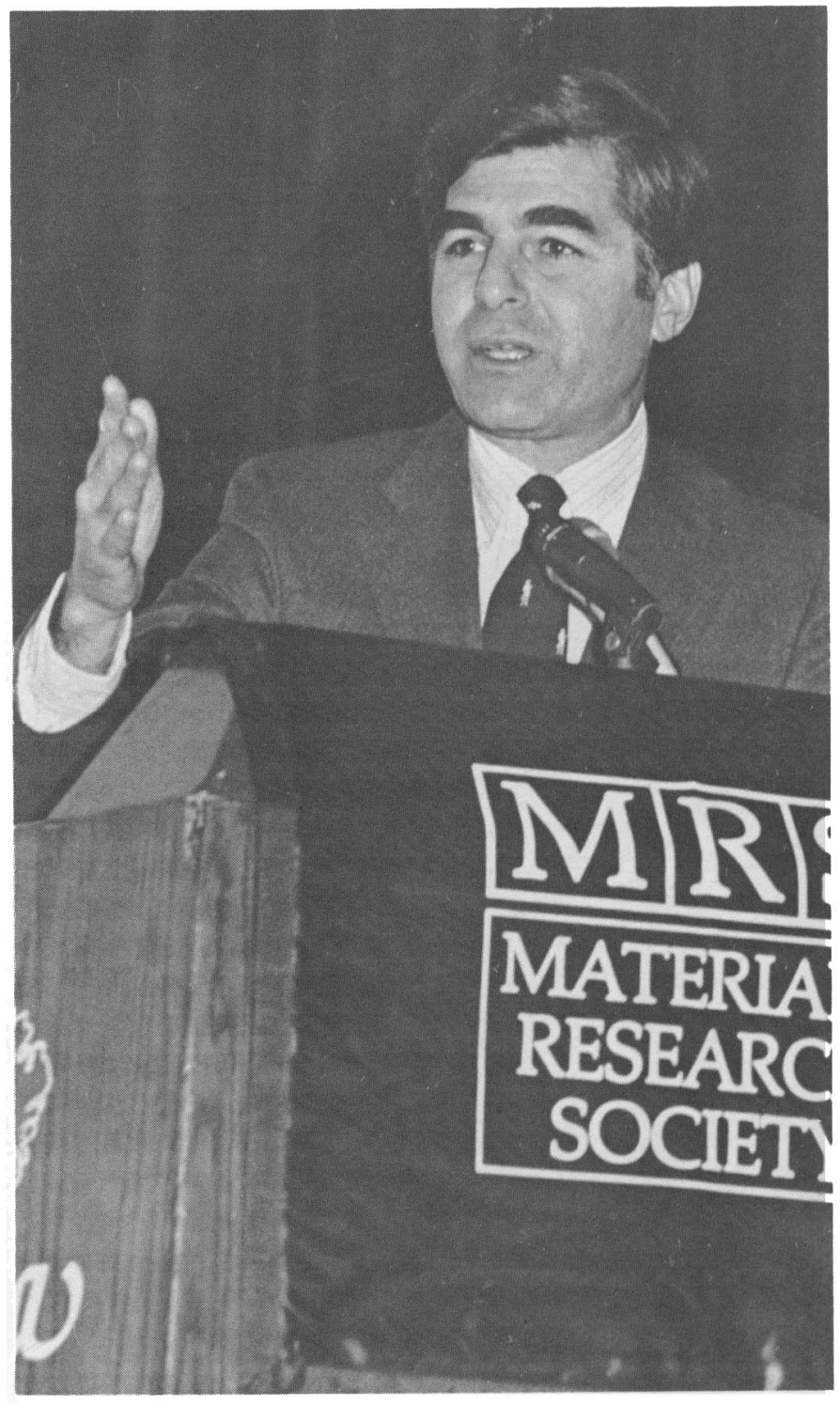

\section{MICHAEL DUKAKIS}

development of that triangle is in the best sense of the word critical to our economic future.

For one thing, you're in a state which has done much better in economic terms over the past decade than most of our sister industrial states precisely because we have a reputation for academic and technological strength, and there's no mystery to why we have what we have on [Highway] 128, and why this state is a center of the high technology, and now increasingly the biotechnology industry. 
It's because we have this reputation and this great strength in an academic and university research sense, and it has made Massachusetts one of the great technological centers. We also have more traditional industries, as well, which are very important to us, and the application of new technology to those older and more mature industries is another essential part of this state's economic strategy. And as the debate goes on nationally over whether or not we ought to have an industrial policy (whatever that means), and whether or not we ought to look to Japan as a model for that kind of thing, I think I can say to you that at the state level in almost every state I know of, governors of both parties, regardless of their ideological leaning, are in the process of developing economic strategies for their states which are designed to take advantage of their respective strengths. And for Massachusetts, the relationship between state house, business community, and university center is absolutely fundamental-absolutely fundamental for our economic future, so much so that as a part of the economic strategy that we are developing for this state, we have identified academic and university centers of excellence; we expect to be investing in them and, in turn, developing industrial strength in and around those academic centers of excellence in ways which are critically important to our economic future and the creation of a healthy economic future and good jobs for our people.

\section{Fostering University/Industry Collaboration}

Let me give you just a couple of examples of what I am talking about and then suggest some things that, as a person elected to politics, we need from you and your colleagues.

We have, as I think some of you know, the University Medical School and the University Hospital in Worcester, which is our major central Massachusetts city. And across the street from that University Medical School is some surplus land which is part of what is the Worcester State Hospital, an old traditional mental hospital, which is now shrinking in size as we care for more people in the community, and do what has happened in most of the states with respect to the problems of the mentally ill and mentally retarded. We have just, in very close cooperation with the Worcester business community, and with the University Medical School, created a biotech park immediately adjacent to the medical school. And we have transferred the land to a non-profit business development corporation organized by the Worcester Chamber of Commerce, which in turn will develop the land, marketed with our assistance to high-tech and biotech companies. That center, that park, we estimate will create some three to four thousand new jobs in the Worcester area, and will be a very nice complement to what is continuing strength in more traditional industries in that part of the state. And the point, obviously, is that it wouldn't be there if there weren't the University Medical School, the University Hospital and the emerging center of medical excellence in that particular location. A public investment, a public facility, but something now which is developing economic strength in very close cooperation with the business community in central Massachusetts.

Out at Amherst, at the University itself, we have a polymer science department, a center of excellence which is one of the best in the world. I expect in a matter of a few days to be announcing a major state investment in that center. Why? Because we expect to be on the cutting edge of what is obviously an important emerging area of technology. And we anticipate that out of that, and out of the state investment, we can develop another economic, as well as research and academic, center of excellence. And we will be systematically looking at similar opportunities all over the Commonwealth and, where appropriate, we will be

\section{The Relationship Between State House, Business Community And University Center Is Absolutely Fundamental For Our Economic Future}

investing public funds in those centers in close cooperation with the business community and with our academic community in ways which we believe will be of enormous importance to the future of this state. Now, is that an industrial policy? I don't know what it is, but I think it makes good sense. And the State of North Carolina, among others, has preceded us in many ways in combining public, private, and university dollars in ways that have been of enormous benefit to that state and to its economic future and the future of its people. So we see this as being an essential element in any kind of economic strategy for a state that cares about the future, and isn't simply prepared to let nature take its course-and I don't know of many states these days that are prepared to do that.

\section{Implementing Informed Governmental Policy}

On the other hand, we have an enormous need, those of us particularly in a position of political leadership, for the kind of expertise and advice and knowledge that you have. Let me just give you three quick examples of issues which are right now before me where the absence of solid scientific and research knowledge, if you will, is making it very difficult for people like myself and the people I work with in elective politics to make decisions that we want to make, and feel that we have a responsibility to make. One is the issue of low-level radioactive waste, and this state produces more than any other state in the country with the possible exception of Pennsylvania; the second is the whole issue of hazardous waste and how we get rid of it or reduce it at its source in the manufacturing process; and the third has to do 
with protecting workers and citizens in our communities from hazardous and toxic wastes-particularly in the work place.

Now, we've just come through a very interesting, very difficult, and yet successful process of putting together what is probably the strongest right-to-know bill in the nation, with the cooperation of the business community and of organized labor, and with a great deal of help from people who know more than I do about toxic wastes and hazardous substances. But I can tell you that the issue of how many and what chemicals ought to be on the list almost defeated our effort to put together a consensus bill that made sense, that business could live with, that protected workers, and at the same time created a framework within which we could add to that list or subtract from it if, in fact, that made sense. And as somebody who almost flunked physics, and hardly has the kind of expertise that exists in this room and across this country, having people who could help us make those kinds of decisions was essential. Coming up with a solution which to some extent delegates to my Commissioner of Public Health responsibility for making those decisions in the future was an effective short-term political solution, but it doesn't in any way minimize the importance of sound, reasoned, and scientifically appropriate and sensible kind of decisions with respect to how we expand on that list. And yet, that was an issue which we had to deal with, which we grappled with for five long, difficult months, until finally we came to a successful resolution, at least for the time being, in the form of feasible legislation.

The issues of hazardous and low-level radioactive waste, regrettably, aren't five-month issues, and one of the things which makes it very difficult for me as a person in a position of political leadership to move on these issues is the kind of community resistance which any governor faces when he goes to a community and suggests that that community be the host community for one of these facilities. And to a very great extent, a lot of that resistance is based on real suspicion about technology, about ways of dealing with the problem-about safe ways of dealing with the problem. Now, people like myself, who have to go to the communities, have to deal with these problems, have to work with the legislature, have to overcome community opposition, often find ourselves in a very, very difficult kind of a situation because, frankly, we don't have the knowledge. We're relying to a very great extent on people like yourselves, and unless you can provide us with that kind of knowledge and expertise, it is virtually impossible for us to come up with an appropriate political solution in the best sense of the word.

\section{Politicians and Scientists Working Together}

So I guess what I'm saying to all of you is that, to a degree which I don't remember, even 20 years ago when I began in this political business, politicians and scientists are going to have to work together. And we're going to have to do the best we can to understand what you're telling us, and you're going to have to do the best you can to put it in English because we need that-we need that if we're going to be able to go to the people who have elected us and say,
"Hey, we've got a solution that makes sense, and I can assure you that this one is safe, is reasonable, and is scientifically valid." I'm not suggesting to you that these problems are going to be easy or that we aren't going to face community opposition. These people are scared, these people are fearful, and, at least in this state and, I suspect, in many other states that are represented here, we have incidents almost every week where we discover a new hazard, a new substance has appeared in somebody's back yard and nobody knew about it. So I will say to you that we are going to have to work together-scientists and politicians, business and university communities-in a way that we didn't anticipate, and we need your advice and counsel and particular expertise. And you, in turn-and I know this is difficult-have got to develop the ability to speak to ordinary citizens in a way that they can understand and appreciate and believe. That's not easy. But it's

In The Dialogue On Public Policy, Government Needs To Listen To ScienceAnd Scientists Need To Talk To Citizens In $A$ Way They Can Understand And Believe absolutely essential if those of us who are given responsibility for fashioning political solutions can do our job.

It's a formidable task. It's a formidable task-and it's not going to get any easier. But to a very great extent, the ability of states likes Massachusetts to fashion an economic future for themselves and their people which takes advantage of this enormous strength in brain power and research technology and university centers that we have will depend on that. I hope that out of your deliberations, out of your work, out of what happens at conferences like this, you'll be able to help us so that we, in turn, can go to the people who we represent with the kind of information and the kind of credibility that makes it possible for us to do our job.

Again, it's a great pleasure to have you here. My thanks for stepping aside so I could celebrate my return to office a year ago, as well as my birthday the next day when some of you were nice enough to show up in the lobby downstairs. This is a very exciting city and a very exciting state these days and I hope you will enjoy it as well as engage in deep, profound, intellectual discussions of your respective fields. Again, I look forward to working with all of you because we need each other, now more than ever.

Thank you all very much. 